\title{
Caracterização bromatológica de oito linhagens de Lentinula edodes (Shiitake) cultivadas em toras de Eucalyptus grandis
}

\author{
Bromatological characterization of Lentinula edodes strains (Shiitake) grown on Eucalyptus grandis logs
}

\author{
Meire Cristina Nogueira de ANDRADE ${ }^{1 \star}$, Marli Teixeira de Almeida MINHONI ${ }^{2}$, Diego Cunha ZIED ${ }^{2}$
}

\begin{abstract}
Resumo
O Lentinula edodes é um alimento de qualidade elevada, sendo rico em proteínas, vitaminas e sais minerais e pobre em calorias e gorduras. No entanto, seu valor nutricional varia em função da linhagem cultivada, do processamento após a colheita, do estágio de desenvolvimento do basidioma e do substrato utilizado. Assim, este trabalho teve como objetivo caracterizar bromatologicamente os basidiomas de oito linhagens de L. edodes (LE-95/01, LE-95/02, LE-95/07, LE-96/17, LE-96/18, LE-98/47, LE-98/55 e LE-96/13), inteiros ou em partes (estípete e píleo), produzidos em toras de E. grandis. Verificou-se que tanto as linhagens de L. edodes como as partes dos basidiomas analisados influenciaram nas respostas nutricionais das amostras. O estípete apresentou as maiores médias de fibra bruta e as menores médias de proteína bruta. O píleo, por sua vez, apresentou as maiores médias de cinzas. Nas avaliações de basidiomas inteiros, as maiores médias, quanto ao teor de proteína bruta, foram obtidas nas linhagens LE-95/07, LE-96/17 e LE-96/18. Já a maior média de fibra bruta foi obtida pela linhagem LE-96/13 de L. edodes. O conteúdo de lipídios do píleo e do estípete não variaram entre as linhagens de L. edodes.
\end{abstract}

Palavras-chave: shiitake; linhagens; cogumelo; valor nutricional.

\begin{abstract}
Lentinula edodes is high quality food which is rich in proteins, vitamins, and minerals and poor in calories and fat. However, its nutritional value is variable according to the strain grown, processing after harvest, development stage of basidiomata, and substrate used. Thus, the objective of this paper was to carry out the bromatological characterization of basidiomatas from eight (LE-95/01, LE-95/02, LE-95/07, LE-96/17, LE-96/18, LE-98/47, LE-98/55 e LE-96/13) L. edodes strains, whole or in parts (stalk and pileus), produced in E. grandis logs. We verified that both the L. edodes strains and parts of basidiomatas analyzed influenced nutritional responses of the samples. The stalk presented the highest raw fiber averages and the lowest raw protein averages. The pileus presented the highest ash averages. For all basidiomatas evaluations, the highest averages concerning raw protein contents were obtained for the strains LE-95/07, LE-96/17 and LE-96/18. The highest raw fiber average was obtained for the $L$. edodes strain LE-96/13. The lipids content of the pileus and the stalk did not vary among $L$. edodes strains. Keywords: shiitake; strains; mushroom; nutritional value.
\end{abstract}

\section{Introdução}

O valor nutritivo de um alimento comumente é expresso de acordo com a composição centesimal ou percentual de grupos homogêneos de substâncias presentes em cem gramas do alimento, sendo eles: umidade, lipídíos, proteínas, carboidratos, fibras e cinzas (SILVA; QUEIROZ, 2002).

Os cogumelos comestíveis constituem-se num alimento de qualidade nutricional elevada (MANZI et al., 2001; RAGUNATHAN; SWAMINATHAN, 2003; YANG et al., 2002) e vêm sendo apontados como uma alternativa para acrescentar a oferta de proteínas em países com alto índice de desnutrição (CHANG; MILES, 1989). No entanto, as características bromatológicas dos cogumelos variam em função da espécie, da linhagem cultivada, do processamento após colheita, do estágio de desenvolvimento do basidioma, da parte do basidioma e do substrato (MINHONI et al., 2007; MANZI et al., 2001; MENEZES, 2005).
Apesar de sua importância e utilização na alimentação humana, observa-se uma carência de estudos sobre a caracterização bromatológica de linhagens de L. edodes quando cultivadas em toras de eucalipto, uma vez que os trabalhos nesta linha de pesquisa fazem estas avaliações utilizando para o cultivo substratos formulados à base de serragem. Não é raro encontrar, no Brasil, bandejas com basidiomas de L. edodes contendo informações nutricionais questionáveis, uma vez que nem sempre as fontes consultadas são informadas e não se sabe sequer se os dados referem-se a cogumelos cultivados no Brasil e sob quais condições.

Informações a respeito da composição dos alimentos, como é o caso do teor de proteínas, lipídios e fibras, vêm se tornando muito importante para profissionais das áreas da saúde e de alimentos, sendo que o consumidor também tem buscado fontes naturais de vitaminas além do interesse por produtos de boa qualidade (FURLANI, 2004).

Recebido para publicação em 22/5/2007

Aceito para publicação em 2/10/2008 (002546)

Coordenação de Pesquisas em Produtos Florestais - CPPF, Instituto Nacional de Pesquisas da Amazônia - INPA, Av. André Araújo, 2936, CP 478, Aleixo, CEP 69060-001,

Manaus - AM, Brasil, E-mail: mcnandrade@hotmail.com

${ }^{2}$ Faculdade de Ciências Agronômicas - FCA, Universidade Estadual Paulista - UNESP, Rua José Barbosa de Barros, 1780, CEP 18603-970, Botucatu - SP, Brasil

${ }^{*}$ A quem a correspondência deve ser enviada 
No Brasil, há poucas literaturas que relatam sobre a qualidade dos cogumelos comestíveis, principalmente dos cultivados em toras, como é o caso do L. edodes. Por esse fato e também pelo constante interesse do consumidor em fontes naturais de vitaminas, o presente trabalho teve como objetivo caracterizar e comparar bromatologicamente os basidiomas de oito linhagens de L. edodes, inteiros ou em partes (píleo e estípete), produzidos em toras de E. grandis.

\section{Material e métodos}

As análises bromatológicas dos basidiomas foram realizadas no Laboratório de Bromatologia da Faculdade de Medicina Veterinária e Zootecnia - Universidade Estadual Paulista, Botucatu - SP. Foram analisadas três amostras de basidiomas desidratados inteiros, três amostras de píleo desidratado e três amostras de estípete desidratado por tratamento, coletados no $1^{\circ}$ fluxo de colheita (após 6 meses de incubação). No total, foram analisadas 72 amostras, com avaliações dos teores de proteína bruta, lipídíos, cinzas e fibra bruta, de acordo com a metodologia de Silva e Queiroz (2002).

\subsection{Determinação de proteína}

Para a determinação de proteína das amostras, pesou-se inicialmente $0,1 \mathrm{~g}$ de material moído e seco em tubo de digestão de $300 \mathrm{~mL}(25 \times 250 \mathrm{~mm})$. Adicionou-se uma medida padronizada de mistura catalizadora (composta de $100 \mathrm{~g}$ de sulfato de potássio, $10 \mathrm{~g}$ de sulfato de cobre) e $3 \mathrm{~mL}$ de ácido sulfúrico concentrado. Em seguida, as amostras foram levadas a um bloco digestor, inicialmente ajustado a uma temperatura de $250{ }^{\circ} \mathrm{C}$, que foi elevada gradativamente até atingir $400{ }^{\circ} \mathrm{C}$. $\mathrm{O}$ extrato ficou pronto quando adquiriu a coloração verde. As amostras foram, então, retiradas do digestor. Após o resfriamento do extrato, foi transferido um pouco de água para o tubo de destilação, o qual, por sua vez, foi colocado em um destilador manual, cuja extremidade de saída ficou mergulhada em ácido bórico. Quando o volume de destilado atingiu $50 \mathrm{~mL}$, o aquecimento foi desligado e o Erlenmeyer e os tubos de digestão foram retirados. O Erlenmeyer contendo a solução foi levado para titular com ácido sulfúrico $(0,05 \mathrm{~N})$. A titulação ocorreu até se verificar visualmente a mudança de cor, quando então foi anotado o volume de ácido utilizado.

Os cálculos efetuados para a determinação da proteína bruta foram:

$\% \mathrm{~N}=[(14 \times 0,05 \times 100) / 100] \times\left(\right.$ Vol. $\mathrm{H}_{2} \mathrm{SO}_{4}-$ Vol. branco $) ; \mathrm{e}$

$\% \mathrm{~PB}=\% \mathrm{~N} \times 6,25$.

em que:

$\% \mathrm{~N}=$ Porcentagem de nitrogênio;

14 = Equivalente do nitrogênio;

0,05 = Normalidade do ácido sulfúrico;

Vol. $\mathrm{H}_{2} \mathrm{SO}_{4}=$ Volume de ácido consumido até o ponto de viragem;

Vol. branco $=$ Volume de ácido consumido até o ponto de viragem do branco; e

$\% \mathrm{~PB}=$ Porcentagem de proteína bruta.

\subsection{Determinação de lipídios}

Para a determinação de lipídios, pesou-se inicialmente $1 \mathrm{~g}$ de amostra em um papel filtro e secou-se em estufa a $105^{\circ} \mathrm{C}$, durante 3 horas (secagem definitiva). Após resfriamento em dessecador por 30 minutos, fez-se o empacotamento da amostra contida no papel filtro, em forma de cartucho. Em seguida, colocou-se a amostra no recipiente próprio do aparelho de extração. Ao Beacker previamente limpo e de peso conhecido, em balança analítica, adicionaram-se $40 \mathrm{~mL}$ de éter de petróleo. Foi, então, colocado sob o condensador e fixado ao anel de rosca. Em seguida, ligou-se a água do condensador, o qual ficou funcionando durante 4 horas, com verificações ocasionais.

Depois da extração ser completada, removeu-se a amostra do recipiente e colocou-se o tubo de vidro, coletor de éter, sob o condensador. Na seqüência, repôs-se o Beaker, levantando-se o aquecedor e destilando-se o éter no tubo coletor. Antes que o Beaker secasse, retirou-se o aquecedor e derramou-se o éter do tubo coletor num recipiente para éter usado. Em seguida, completou-se a secagem do Beaker na estufa a $105^{\circ} \mathrm{C}$, por 30 minutos. Finalmente, o Beaker foi esfriado num dessecador à temperatura ambiente e pesado. A diferença entre este último peso e o Beaker vazio correspondeu ao peso do lipídios.

\subsection{Determinação de cinzas}

$\mathrm{Na}$ determinação de cinzas, colocaram-se inicialmente os cadinhos de porcelana vazios na mufla a $550-600{ }^{\circ} \mathrm{C}$, durante 15 minutos e, em seguida, foram esfriado em dessecador, durante 1 hora. Posteriormente, pesou-se o cadinho vazio e depois com $1 \mathrm{~g}$ da amostra e procedeu-se à incineração, até a obtenção de cinza clara, durante 4 horas a $600^{\circ} \mathrm{C}$. Após este tempo, esfriaram-se as amostras em dessecador e fizeram-se as pesagens.

\subsection{Determinação de fibra bruta}

Inicialmente, pesaram-se $2 \mathrm{~g}$ de amostra seca e os colocaram em copo de $600 \mathrm{~mL}$, próprio para ser adaptado ao digestor. Em seguida, adicionaram-se $100 \mathrm{~mL}$ de $\mathrm{H}_{2} \mathrm{SO}_{4}$ a $1,25 \%$, fervente, à amostra e a colocaram no aparelho digestor. A fervura foi iniciada dentro de 1 minuto quando, então, foi prolongada por 30 minutos. Ao final da digestão ácida, procedeu-se à filtração, fazendo-se lavagens sucessivas com água destilada fervente sobre o resíduo, até a neutralização do material. O material retido no linho foi quantificativamente transferido para o copo de digestão, usando-se, para essa transferência, $100 \mathrm{~mL}$ da solução de $\mathrm{NaOH}$ a $1,25 \%$, fervente, quando, então, procedeu-se à digestão básica, seguindo-se os mesmos princípios da digestão ácida.

Após as hidrólises, o resíduo (fibra e minerais) foi transportado, quantitativamente, com auxílio de uma piseta com álcool, para o cadinho filtrante adaptado a um kitazato e este a uma bomba de vácuo. Em seguida, lavou-se o material com álcool $(20 \mathrm{~mL})$ e, posteriormente, com éter $(10 \mathrm{~mL})$, a fim de facilitar a secagem e eliminar compostos provenientes das digestões. Na seqüência, fez-se a secagem dos cadinhos em estufa a $105^{\circ} \mathrm{C}$, e eles foram levados ao dessecador. A pesagem forneceu o peso do cadinho, da fibra bruta e dos minerais. Finalmente, fez-se a calcinação em mufla a $500^{\circ} \mathrm{C}$, durante 2 horas, quando toda a fibra foi oxidada, restando somente minerais insolúveis. A diferença de peso, antes e após a calcinação, forneceu o peso da fibra bruta da amostra. 


\subsection{Delineamento experimental e análise estatística}

O delineamento experimental foi inteiramente casualizado, em esquema fatorial $8 \times 3$ ( 8 linhagens de L. edodes $\times 3$ partes do basidiomas) e 3 repetições. A unidade experimental constou de uma amostra mista de cogumelos desidratados (100 g) inteiros ou em partes, de acordo com cada tratamento. Os dados foram submetidos à análise de variância e as médias foram comparadas pelo teste de Tukey (SNEDECOR; COCHRAN, 1972), utilizando-se o programa estatístico Sisvar 4.2 desenvolvido pelo Departamento de Ciências Exatas, da Universidade Federal de Lavras, MG (UFLA).

\section{Resultados e discussão}

Na Tabela 1, encontram-se os valores de $F$ obtidos na análise de variância de proteína bruta, lipídios, cinzas e fibra bruta das linhagens LE-95/01, LE-95/02, LE-95/07, LE-96/17, LE-96/18, LE-98/47, LE-98/55 e LE-96/13 de L. edodes, cultivadas em toras de E. grandis.

Houve efeito da linhagem (L), da parte do basidioma (P) e da interação L x P para as variáveis proteína, cinzas e fibra bruta (Tabela 1). Já para a variável lipídios, houve efeito da parte do basidioma (P) e da interação L x P. Shibata e Demiate (2003), avaliando a composição química do cogumelo Agaricus blazei, concluíram que há diferenças nutricionais entre duas linhagens de A. blazei testadas, sendo a linhagem AbM mais rica em fibras e minerais, enquanto que a linhagem Jun-17 apresentou teor mais elevado de carboidratos.

Os valores médios dos teores de proteína, lipídios, cinzas e fibra bruta das linhagens LE-95/01, LE-95/02, LE-95/07, LE-96/17, LE-96/18, LE-98/47, LE-98/55 e LE-96/13 de L. edodes estão apresentados na Tabela 2.

As médias de proteína bruta de amostras de cogumelos inteiros variaram de 18,67 a $22,67 \%$, sendo que as linhagens LE-95/07, LE-96/17 e LE-96/18 obtiveram as maiores médias (Tabela 2). Longvah e Deosthale (1998), com amostras desidratadas adquiridas no mercado local de Manipur/Índia, obtiveram média muito próxima, ou seja, 22,8\%. Valores semelhantes foram obtidos por Yang et al. (2001), que analisando duas amostras de L. edodes, encontraram médias de 19,7 e 20,5\% de proteína. Chang e Miles (1989) apontam que o L. edodes contém, em base seca, de 13,4 a 17,5\% de proteína bruta, cujos valores são inferiores aos resultados obtidos no presente trabalho.

Tabela 1. Valores de $\mathrm{F}$ obtidos na análise de variância de proteína bruta, lipídeos, cinzas e fibra bruta das linhagens LE-96/17, LE-95/02, LE-95/07, LE-98/55, LE-96/18, LE-95/01, LE-96/13 e LE-98/47 de L. edodes, cultivadas em toras de Eucalyptus grandis.

\begin{tabular}{lccrc}
\hline Fator de variação & Proteína & Lipídios & Cinzas & Fibra bruta \\
\hline Linhagem (L) & $19,9^{* *}$ & $1,94 \mathrm{~ns}$ & $9,11^{* *}$ & $43,48^{* *}$ \\
Parte (P) & $815,51^{* *}$ & $4,07^{*}$ & $155,21^{\star *}$ & $1.671,49^{* *}$ \\
L x P & $4,98^{* *}$ & $2,43^{\star}$ & $4,44^{* *}$ & $35,71^{* *}$ \\
CV $(\%)$ & 4,95 & 16,84 & 8,00 & 4,06 \\
\hline
\end{tabular}

${ }^{\star *}$ Significativo ao nível de $1 \%$; ${ }^{\star}$ significativo ao nível de $5 \%$; e ns = não significativo.
Nas amostras do píleo de basidiomas, as médias de proteína bruta variaram de 17,75 a $23,80 \%$, sendo que as linhagens LE-96/17, LE-96/18, LE-98/47 e LE-96/13 obtiveram as maiores médias. Nas amostras de estípete, as médias variaram de 10,21 a 13,64\%, sendo que as linhagens LE-96/17, LE-96/18 e LE-96/13 obtiveram as maiores médias. Já a linhagem LE-95/01 obteve média intermediária. Finalmente, as linhagens LE-95/02, LE-95/07, LE-98/47 e LE-98/55 obtiveram as menores médias. Comparando-se o teor de proteína bruta entre as partes do basidioma para cada linhagem, verifica-se que o estípete apresentou as menores médias em relação ao píleo ou ao basidioma inteiro (Tabela 2).

As médias de lipídios em amostras de basidiomas inteiros variaram de $2 \%$ a 3, sendo que as linhagens LE-98/55 e LE-96/13 obtiveram as maiores médias, diferindo significativamente, ao nível de 5\% de probabilidade, das linhagens LE-95/01, LE-95/07, LE-96/17 e LE-98/47. Já os basidiomas das linhagens LE-95/02 e LE-96/18 obtiveram médias intermediárias (Tabela 2). Chang e Miles (1989) citam que os cogumelos comestíveis apresentam uma baixa quantidade de lipídios, variando de 1,1 a 8,3\% em base seca. Longvah e Deosthale (1998), analisando cogumelos comestíveis provenientes do nordeste da Índia, encontram 2,1\% de lipídios em base seca. Cogumelos comercializados em Taiwan e analisados por Yang et al. (2001) apresentaram teores de lipídios de $2,16 \%$ (P. ostreatus) a 6,3\% (L. edodes).

Nas amostras do píleo de basidiomas, as médias de lipídios variaram de 2,06 a 2,80\%. No entanto, esta variação não foi significativa entre as linhagens de L. edodes. O mesmo foi observado nas amostras de estípete, cujas médias situavam-se entre 1,58 e 2,35\% (Tabela 2).

Comparando-se o teor de lipídios entre o basidioma e partes deste para cada linhagem, verifica-se que, para a linhagem LE-95/07, o píleo apresentou maior média que o estípete. Na linhagem LE-98/47, o píleo apresentou maior média que o basidioma inteiro. Na linhagem LE-98/55, o basidioma inteiro apresentou maior média que o estípete. Por sua vez, na linhagem LE-96/13, o basidioma inteiro apresentou maior média que o píleo e o estípete (Tabela 2).

As médias de cinzas em amostras de basidiomas inteiros variaram de 3 a 3,88\%, sendo que a linhagem LE-96/17 obteve a maior média, diferindo significativamente, ao nível de $5 \%$ de probabilidade, das linhagens LE-95/01, LE-98/55 e LE-96/13. As linhagens LE-95/02, LE-95/07, LE-96/18 e LE-98/47 obtiveram médias intermediárias (Tabela 2). Estes resultados foram relativamente inferiores aos obtidos por Longvah e Deosthale (1998) que, avaliando basidiomas de L. edodes nativos do nordeste da Îndia, obtiveram valor médio de $6 \%$ de cinzas.

Nas amostras de píleo de basidiomas, as médias de cinzas variaram de 4,11 a 5,15\%, sendo que as linhagens LE-95/01 e LE-96/13 obtiveram as maiores médias, diferindo significativamente, ao nível de 5\% de probabilidade, das linhagens LE-95/02, LE-95/07, 96/18 e LE-98/55. As linhagens LE-96/17 e LE-98/47 obtiveram médias intermediárias. Por sua vez, nas amostras de estípete de basidiomas, as médias variaram de 2,54 a 4,12\%, sendo as maiores médias obtidas pelas linhagens LE-95/01 e LE-96/17 (Tabela 2). 
Tabela 2. Valores totais médios de proteína bruta, lipídios, cinzas e fibra bruta das linhagens LE-95/01, LE-95/02, LE-95/07, LE-96/17, LE-96/18, LE-98/47, LE-98/55 e LE-96/13 de L. edodes, em função das partes do basidioma analisado.

\begin{tabular}{|c|c|c|c|}
\hline \multirow[t]{2}{*}{ Linhagens } & \multicolumn{3}{|c|}{ Partes do basidioma } \\
\hline & Inteiro & Píleo & Estípete \\
\hline \multicolumn{4}{|c|}{ Proteína bruta (\%) } \\
\hline LE-95/01 & $20,33^{\mathrm{BCa}}$ & $20,03^{\mathrm{Ba}}$ & $12,30^{\mathrm{ABCb}}$ \\
\hline LE-95/02 & $20,33^{\mathrm{BCa}}$ & $19,21^{\mathrm{Ca}}$ & $11,32^{\mathrm{BCb}}$ \\
\hline LE-95/07 & $21,00^{\mathrm{ABa}}$ & $17,75^{\mathrm{Cb}}$ & $10,21^{\mathrm{Cc}}$ \\
\hline LE-96/17 & $22,67^{\mathrm{Aa}}$ & $23,59^{\mathrm{Aa}}$ & $12,59^{\mathrm{ABb}}$ \\
\hline LE-96/18 & $22,67^{\mathrm{Aa}}$ & $23,80^{\mathrm{Aa}}$ & $13,64^{\mathrm{Ab}}$ \\
\hline LE-98/47 & $20,00^{\mathrm{BCb}}$ & $21,89^{\mathrm{ABa}}$ & $11,17^{\mathrm{BCc}}$ \\
\hline LE-98/55 & $20,00^{\mathrm{BCa}}$ & $19,97^{\mathrm{Ba}}$ & $11,03^{\mathrm{BCb}}$ \\
\hline LE-96/13 & $18,67^{\mathrm{Cb}}$ & $21,64^{\mathrm{ABa}}$ & $13,00^{\mathrm{ABC}}$ \\
\hline \multicolumn{4}{|c|}{ Lipídios (\%) } \\
\hline LE-95/01 & $2,00^{\mathrm{Ba}}$ & $2,06^{\mathrm{Aa}}$ & $2,35^{\mathrm{Aa}}$ \\
\hline LE-95/02 & $2,33^{\mathrm{ABa}}$ & $2,77^{\mathrm{Aa}}$ & $2,19^{\text {Aa }}$ \\
\hline LE-95/07 & $2,00^{\mathrm{Bab}}$ & $2,39^{\mathrm{Aa}}$ & $1,58^{\mathrm{Ab}}$ \\
\hline LE-96/17 & $2,00^{\mathrm{Ba}}$ & $2,29^{\mathrm{Aa}}$ & $2,25^{\mathrm{Aa}}$ \\
\hline LE-96/18 & $2,33^{\mathrm{ABa}}$ & $2,50^{\mathrm{Aa}}$ & $2,30^{\mathrm{Aa}}$ \\
\hline LE-98/47 & $2,00^{\mathrm{Bb}}$ & $2,80^{\mathrm{Aa}}$ & $2,23^{\mathrm{Aab}}$ \\
\hline LE-98/55 & $3,00^{\mathrm{Aa}}$ & $2,51^{\mathrm{Aab}}$ & $2,14^{\mathrm{Ab}}$ \\
\hline LE-96/13 & $3,00^{\mathrm{Aa}}$ & $2,06^{\mathrm{Ab}}$ & $1,88^{\mathrm{Ab}}$ \\
\hline \multicolumn{4}{|c|}{ Cinzas (\%) } \\
\hline LE-95/01 & $3,10^{\mathrm{Bb}}$ & $4,97^{\mathrm{ABa}}$ & $3,44^{\mathrm{ABb}}$ \\
\hline LE-95/02 & $3,57^{\mathrm{ABb}}$ & $4,17^{\mathrm{Ca}}$ & $2,54^{\mathrm{Cc}}$ \\
\hline LE-95/07 & $3,13^{\mathrm{ABb}}$ & $4,21^{\mathrm{BCa}}$ & $3,29^{\mathrm{BCb}}$ \\
\hline LE-96/17 & $3,88^{\mathrm{Ab}}$ & $4,85^{\mathrm{ABCa}}$ & $4,12^{\mathrm{Ab}}$ \\
\hline LE-96/18 & $3,51^{\mathrm{ABb}}$ & $4,11^{\mathrm{Ca}}$ & $2,69^{\mathrm{BCC}}$ \\
\hline LE-98/47 & $3,51^{\mathrm{ABb}}$ & $4,50^{\mathrm{ABCa}}$ & $2,89^{\mathrm{BCC}}$ \\
\hline LE-98/55 & $3,00^{\mathrm{Bb}}$ & $4,26^{\mathrm{BCa}}$ & $3,00^{\mathrm{BCb}}$ \\
\hline LE-96/13 & $3,00^{\mathrm{Bb}}$ & $5,15^{\mathrm{Aa}}$ & $3,24^{\mathrm{BCb}}$ \\
\hline \multicolumn{4}{|c|}{ Fibra bruta (\%) } \\
\hline LE-95/01 & $8,04^{\mathrm{Bc}}$ & $9,26^{\mathrm{CDb}}$ & $16,86^{\mathrm{Ca}}$ \\
\hline LE-95/02 & $8,07^{\mathrm{Bc}}$ & $11,39^{\mathrm{ABb}}$ & $14,95^{\mathrm{Da}}$ \\
\hline LE-95/07 & $9,05^{\mathrm{Bc}}$ & $11,65^{\mathrm{Ab}}$ & $21,77^{\text {Aa }}$ \\
\hline LE-96/17 & $9,03^{\mathrm{Bb}}$ & $8,99^{\mathrm{Db}}$ & $14,36^{\mathrm{Da}}$ \\
\hline LE-96/18 & $8,85^{\mathrm{Bc}}$ & $10,27^{\mathrm{BCb}}$ & $16,69^{\mathrm{Ca}}$ \\
\hline LE-98/47 & $8,56^{\mathrm{Bc}}$ & $11,28^{\mathrm{ABb}}$ & $14,35^{\mathrm{Da}}$ \\
\hline LE-98/55 & $8,33^{\mathrm{Bc}}$ & $11,87^{\mathrm{Ab}}$ & $18,63^{\mathrm{Ba}}$ \\
\hline LE-96/13 & $11,44^{\mathrm{Ab}}$ & $9,29^{\mathrm{CDc}}$ & $15,34^{\mathrm{Da}}$ \\
\hline
\end{tabular}

*Para cada variável, médias seguidas de letras maiúsculas iguais em cada coluna e minúsculas em cada linha não diferem ente entre si (Tukey, 5\%).

As médias de fibra bruta de amostras de basidiomas inteiros variaram de 8,04 a 11,44\%, sendo que a linhagem LE-96/13 obteve a maior média (Tabela 2). Longvah e Deosthale (1998) obtiveram média de $2,1 \%$ de fibra bruta, inferior às do presente trabalho.

Nas amostras de píleo de basidiomas, as médias de fibra bruta variaram de 8,99 a $11,87 \%$, sendo que as maiores médias foram obtidas pelas linhagens LE-95/02, LE-95/07, LE-98/47 e LE-98/55. Por fim, nas amostras de estípete de basidiomas, as médias de fibra bruta variaram de 14,35 a $21,77 \%$, sendo a maior média obtida pela linhagem LE-95/07 (Tabela 2). Valores superiores foram citados por Cheung (1996) que, analisando o píleo e o estípete de três cogumelos (L. edodes, L. shimeji e Pleurotus) em base seca, verificou que para o L. edodes o valor de fibra alimentar foi de 44,9 e 52,7\%; para o L. shimeji foi de 44 e 39,2\% e para o Pleurotus spp., 42,6 e 42,2\% para o píleo e o estípete, respectivamente.

Comparando o teor de fibra bruta das partes do basidioma para cada linhagem, verifica-se que o estípete apresentou as maiores médias em relação ao píleo ou ao basidioma inteiro (Tabela 2).

\section{Conclusões}

As linhagens de L. edodes, assim como as partes dos basidiomas analisados, influenciaram na composição das amostras.

O estípete obteve as maiores médias de fibra bruta e as menores médias de proteína bruta. 
O píleo obteve as maiores médias de cinzas.

Nos basidiomas inteiros, as maiores médias, quanto ao teor de proteína bruta, foram obtidas nas linhagens LE-95/07, LE-96/17 e LE-96/18.

O maior conteúdo de fibra bruta dos basidiomas inteiros ocorreu na linhagem LE-96/13 de L. edodes.

O conteúdo de lipídios do píleo e do estípete não variaram entre as linhagens de L. edodes.

\section{Referências bibliográficas}

CHANG, S. T.; MILES, P. G. Edible mushrooms and their cultivation. Boca Raton: CRC Press, 1989.

CHEUNG, P. C. K. Dietary fiber content and composition of some edible mushroom fruiting bodies and mycelia. Journal of agricultural and food chemistry, v. 44, n. 2, p. 468-471, 1996.

FURLANI, R. P. Z. Valor nutricional de cogumelos cultivados no Brasil. Campinas, 2004. 88p. Tese - (Doutorado em Ciência de Alimentos), Faculdade de Engenharia de alimentos, Universidade Estadual de Campinas - UNICAMP.

LONGVAH, P.; DEOSTHALE, Y. G. Compositional and nutritional studies on edible wild mushroom from northeast Índia. Food chemistry, v. 63, n. 3, p. 331-334, 1998.
MANZI, P.; AGUZZI, A.; PIZZOFERRATO, L. Nutritional value of mushrooms widely consumed in Italy. Food Chemistry, v. 73, n. 3, p. 321-325, 2001.

MENEZES, M. C. Efeito do Agaricus blazei (Murrill) ss. Heinemann no estado nutricional e na bioquímica hepática em portadores de hepatite C. Botucatu, 2005. 113p. Dissertação - (Mestrado), Faculdade de Medicina de Botucatu, Universidade Estadual Paulista - UNESP.

MINHONI, M. T. A.; ANDRADE, M.C. N.;ZIED, D. C.; KOPYTOWSKI FILHO, J. Cultivo de Lentinula edodes (Berk.) Pegler - (Shiitake). 3 ed. Botucatu: FEPAF, 2007.

RAGUNATHAN, R.; SWAMINATHAN, K. Nutritional status of Pleurotus spp. grown on various agro-wastes. Food Chemistry, v. 80, n. 3, p. 371-375, 2003.

SHIBATA, C. K. R.; DEMIATE, I. M. Cultivo e análise da composição química do cogumelo do sol (Agaricus blazei Murrill). Publ. UEPG Ci. Biol. Saúde, v. 9, n. 2, p. 21-32, 2003.

SILVA, D. J.; QUEIROZ, A. C. Análise de alimentos: métodos químicos e biológicos. Viçosa: UFV, 2002.

SNEDECOR, G. W. E.; COCHRAN, W. G. Statistical methods. 6 ed. Ames: Iowa State Univ., 1972.

YANG, J.; LIN, H.; MAU, J. Antioxidant properties of several commercial mushrooms. Food Chemistry, v. 77, n. 2, p. 229-235, 2002.

YANG, J. H.; LIN, H. C.; MAU, J. L. Non-volatile taste components of several commercial mushrooms. Food Chemistry, v. 72, n. 4, p. $465-471,2001$. 